\title{
Direitos humanos fundamentais e a (re)conciliação entre direito e moral em uma perspectiva pós-positivista
}

\author{
Fundamental human rights and (re)conciliation between law and \\ morality in a perspective post positivist
}

Jordão Violin, Amélia Sampaio Rossi*

Pontifícia Universidade Católica do Paraná, Curitiba, PR, Brasil

\section{Resumo}

No constitucionalismo contemporâneo ou neoconstitucionalismo os princípios constitucionais acolhem, normativamente, os principais valores e opções morais e políticas da comunidade. Os direitos fundamentais, muitas vezes são erigidos sob a forma de princípios normativos, que por sua vez encontram abrigo nos Textos Constitucionais atuais. A compreensão mais extensa de Dworkin sobre o que é o Direito, em uma perspectiva interpretativa, não se explica e nem se compreende sob a visão do positivismo jurídico. Não é despiciendo lembrar que um dos pressupostos metodológicos que acode a toda a doutrina positivista (e são os mais variados tipos de positivismo existente) é a separação entre Direito e Moral. Assim, a compreensão dos princípios normativos, com a sua potencial recorrência a valores e opções políticas fundamentais, quebra esta suposta separação, ainda mais quando se encontram estes princípios em uma Constituição que se

JV: Doutorando em Direito, e-mail: jordao.violin@pucpr.br.

ASR: Doutora em Direito, e-mail: amelia.rossi@pucpr.br 
estabelece no centro de importância e significado de toda a ordem jurídica, irradiando os seus princípios constitucionais na compreensão e interpretação do sistema jurídico e consequentemente, rematerializando e ressubstancializando todo o Direito. Portanto, na perspectiva mais extensa do Direito, ressignificada pelo neoconstitucionalismo, uma Constituição que não abrigue direitos humanos fundamentais, sob a forma de princípios normativos e em caráter emancipatório, não pode ser reconhecida como uma verdadeira Constituição. É o que se pretende refletir e demonstrar no presente artigo, com o emprego de pesquisa bibliográfica em autores autorizados sobre o tema.

Palavras-chave: Direitos humanos fundamentais. Pós-positivismo. Neoconstitucionalismo. Dignidade humana.

\section{Abstract}

In contemporary constitutionalism or neoconstitutionalism, principles host, normatively, the main community values and moral and political choices. Fundamental rights are often erected in the form of normative principles, which in turn, are included in the current Constitutional Texts. Dworkin's most extensive understanding on what is the law, in an interpretative perspective, is not explained nor is understood under the vision of legal positivism. It is not insignificant to remember that one of the methodological assumptions on which the entire positivist doctrine is founded (and there are all kinds of positivisms) is the separation between law and morals. Thus, understanding the normative principles, with its potential recurrence to fundamental values and political choices, fulfills this separation, especially when these principles are stated in a constitution that is in the center of importance and significance of the whole legal system, radiating its constitutional principles in the task of understanding and interpreting the legal system and consequently, giving the law a whole new content. Therefore, in the longer perspective of law, re-signified by the neoconstitutionalism, a constitution that does not harbor fundamental human rights, in the form of normative principles and with emancipatory characteristic, can not be recognized as a true constitution. This is what is intended to reflect and demonstrate in this article, with the use of literature in authorized authors on the subject.

Keywords: Fundamental human rights. Post positivism. Neoconstitutionalism. Human dignity. 


\section{Introdução}

O atual paradigma jurídico é fruto direto da traumática experiência da segunda guerra mundial. O extermínio de milhões de pessoas sob o amparo da lei demonstrou às gerações que se seguiram a necessidade de superação do Estado Legalista.

A redução do direito à lei escrita foi um movimento longo, no qual suas origens podem ser encontradas na filosofia iluminista que, num primeiro momento, vinculou-se sem reservas ao jusnaturalismo: um direito de estrutura objetiva, fundado numa ideia de justiça anterior à lei. Desse apriorismo decorreu a crença na existência de normas jurídicas absolutas, universalmente obrigatórias e imutáveis. Ou seja, o homem possuiria direitos naturais anteriores à constituição de quaisquer vínculos sociais ou civis. Direitos verdadeiramente metafísicos, identificados com a própria noção de justo (CASSIRER, 1997, p. 327-334).

O jusracionalismo moderno caracterizou-se pela tentativa de construir um sistema jurídico racional, matematicamente demonstrável, a partir de grandes standards de justiça universal. O Direito deixou de ser uma ciência argumentativa para ser tornar-se uma ciência meramente explicativa. Fruto do mentalismo conceitual, afastou-se dos fatos e enclausurou-se numa estrutura lógico-dedutiva (SILVA, 2004, p. 96-97).

O movimento codificatório que se seguiu foi apenas uma consequência dessa filosofia universalista. Os códigos modernos eram pautados por uma ordem intrínseca e por um conjunto de disposições pretensamente atemporais. Eram, portanto, empreendimentos de sistematização de um Direito natural fundado numa razão supostamente imutável e universal (HESPANHA, 2005, p. 330).

Há, aqui, um ponto de ruptura fundamental para a compreensão dos eventos que se seguiram. A positivação do direito gerou a falsa sensação de que o direito racional fora transposto para os códigos. Ou seja, a partir da codificação, não seria mais necessário pensar 
o Direito. Bastaria aplicar a lei, agora positivada em códigos sistematizados, pretensamente completos e universais. ${ }^{1}$

A invocação de princípios exteriores ao sistema do Direito positivo foi, gradualmente, perdendo sua legitimidade, até o ponto em que se afirmou não haver direito senão o Direito legislado. Qualquer tentativa de interpretação era vista como uma ilegítima tentativa de fraudar a vontade do legislador (rectius, do povo), substituindo-a pela vontade do aplicador. O Direito foi, finalmente, reduzido à lei escrita.

O apego ao Direito positivo, típico do positivismo jurídico, não encontrou limites para a vontade da maioria. Se o Direito equivale à lei, e esta é resultado de um processo de votação majoritário, então uma maioria pode transformar em lei todas as suas vontades. Não por acaso, a decadência do positivismo "é emblematicamente associada à derrota do fascismo na Itália e do nazismo na Alemanha, regimes que promoveram a barbárie sob a proteção da legalidade" (BARROSO, 2007, p. 4).

É fácil perceber como esse Direito de estrutura normativa, e não valorativa, contribuiu para o extermínio de milhões de pessoas. Em primeiro lugar, ao retirar do indivíduo a capacidade de fazer um juízo de valor sobre a norma, faz-se do direito um fim em si mesmo. Trata-se de um direito vazio de valores, formado por normas sem alma, já que o conteúdo do texto normativo seria moralmente irrelevante. Diante de um direito reduzido à lei escrita, o indivíduo não precisa pensar. Basta cumprir.

Adicionalmente, o apego à norma como simples dever-ser, independentemente de seu conteúdo, gerava uma sensação de pertencimento. A observância da norma ligava o indivíduo à coletividade, integrando-o ao todo. Esse mecanismo mimético de reprodução das

1 Daí se afirmar que a codificação foi, todavia, simultaneamente o ápice e a ruína da teoria do direito natural. Com efeito, "com a promulgação dos códigos, principalmente do napoleônico, o Jusnaturalismo exauria a sua função no momento mesmo em que celebrava 0 seu triunfo. Transposto 0 direito racional para o código, não se via nem admitia outro direito senão este". BOBBIO, Norberto; MATEUCCI, Nicola; PASQUINO, Gianfranco. Dicionário de Política. São Paulo: Imprensa Oficial, 1999. v. 1, p. 659. 
normas reforçava a identidade coletiva, aumentando a tensão entre maioria ariana e seus (supostos) antagonistas. ${ }^{2}$

Ao mesmo tempo, a aplicação cega do Direito legislado retirava do indivíduo a responsabilidade por seus atos. O cumprimento da lei não era um ato volitivo individual, mas um dever jurídico. Não se poderia exigir do indivíduo conduta diversa. A prisão e morte de judeus, ao final, somente poderia ser atribuída ao "Regime" - uma instituição abstrata, despersonalizada, incapaz de gerar no indivíduo o sentimento de culpa por seus próprios atos. ${ }^{3}$

O movimento de reabertura do ordenamento a um conteúdo moral, após a 2 ${ }^{a}$ Guerra Mundial, decorreu exatamente da percepção de que o Direito deve refletir o conteúdo axiológico da sociedade, e que determinada parcela desse conteúdo deve estar além da esfera de disponibilidade do legislador. Um Direito indiferente à moral e esvaziado de preceitos éticos não se mostrara capaz de conter a barbárie. Assistiu-se, então, à positivação de princípios e valores nas constituições. Esse documento, porque dotado de superioridade formal, passou a encerrar limites ao poder e à supremacia da lei. É essa reinserção de valores morais no direito que caracteriza, em essência, o neoconstitucionalismo. ${ }^{4}$

Em outras palavras, a Constituição passou a ser encarada não mais como uma carta meramente política, mas como um conjunto de normas hierarquicamente superiores que limitam o Estado e a

2 Para René Girard, a mimésis (o desejo de ser como o outro, o desejo de sentir-se integrado, 0 ato de imitar para ser como os demais) seria o ponto de partida da antropologia. Para 0 autor, é justamente 0 comportamento mimético que desencadeia todas as rivalidades, até o ponto em que as sociedades resolvem seus antagonismos por meio de um mecanismo sacrificial seja ele incidente sobre uma única vítima (como Jesus Cristo) ou sobre uma minoria (como os judeus, na Alemanha nazista). Sobre o tema, v. GIRARD, René. Coisas ocultas desde a fundação do mundo: a revelação destruidora do mecanismo vitimário. São Paulo: Paz e Terra, 2008.

3 Sobre o tema, v. ARENDT, Hannah. Eichmann em Jerusalém. São Paulo: Cia. das Letras, 1999, p. 32 e ss.

4 Para Reinaldo Pereira e Silva, "Tal ambiente político-ideológico, a partir da segunda metade do século XX, envolve a superação de uma concepção de constitucionalismo pautada pela identificação acrítica do direito à lei e da lei a toda deliberação legislativa arrebatada pela idéia formalista da vontade da maioria." PEREIRA E SILVA, Reinaldo. Reflexões sobre a pré-compreensão constitucional: a dignidade da pessoa humana como condição de possibilidade de sentido. In: Revista Sequência, n. 50, jul 2005, p. 190.

Rev. Filos., Aurora, Curitiba, v. 28, n. 43, p. 167-186, jan./abr. 2016 
própria vontade majoritária para garantir o respeito a determinados valores intangíveis.

Os direitos fundamentais nessa nova construção assumem importância central. Deixam de ser simples normas programáticas ou meras declarações de intenções. Passam a ser vistos como normas dotadas de uma dimensão subjetiva e de uma dimensão objetiva. A primeira decorre do fato de que direitos fundamentais, efetivamente, fundamentam pretensões de seus titulares. Ou seja, permitem que se exija o cumprimento de deveres positivos ou negativos. Já a dimensão objetiva denota que os direitos fundamentais são a base de valores a partir da qual todo o ordenamento jurídico deve ser construído (MENDES, 2009, p. 2).

Tal mudança de perspectiva exige o realinhamento da própria teoria da separação dos poderes. Afinal, se os valores fundamentais têm natureza de norma jurídica, podendo assumir a forma de regras ou princípios, e se a jurisdição sempre foi caracterizada pela aplicação imparcial do direito, então a Constituição assume posição central na teoria da jurisdição. ${ }^{5}$ Assim, como passa a iluminar a elaboração e atuação das leis, limitando o poder do legislador e orientando a função do administrador. ${ }^{6}$

\section{A mudança de paradigmas: superação da perspectiva positivista e triunfo do neoconstitucionalismo em uma perspectiva pós-positivista}

Em 1977, com a sua obra Levando os Direitos a Sério, DWORKIN (2007. p.28) se propôs estabelecer uma compreensão do Direito diversa daquela estabelecida até então pelo(s) positivismo(s) jurídico(s). Para o autor, as posições básicas do positivismo (embora a sua contrariedade se dê em relação ao positivismo jurídico mais

5 Para um conceito de jurisdição como atividade direcionada à concretização de direitos fundamentais, v. FISS, Owen. The forms of justice. Harvard Law Review, n. 93, nov. 1979. No Brasil, v. MARINONI, Luiz Guilherme. Teoria geral do processo. 4. ed. São Paulo: RT, 2010, p. 98-99.

6 Para um conceito de função administrativa calcado nos direitos fundamentais, v. JUSTEN FILHO, Marçal. Curso de direito administrativo. 5. ed. São Paulo: Saraiva, 2010, p. 39-40. 
avançado defendido por Hart) se estabelecem em torno da ideia de que o Direito seria um sistema complexo de regras, estatuídas pelo Poder Público, que definiriam o comportamento de uma comunidade. Atente-se para o termo: regras, não princípios. Para serem reconhecidas como válidas, essas regras seriam submetidas a critérios de análise relacionados à forma pela qual foram criadas, não pelo conteúdo que veiculam (aqui se encontra a ideia da regra secundária de reconhecimento de Hart).

Ora, se o conjunto dessas regras constitui o próprio Direito, um caso determinado que não encontre solução na regra estabelecida deverá ser decidido por meio da discricionariedade judicial. Ou seja, o julgador recorreria a elementos externos ao direito para criar a solução do caso concreto. Ao fazê-lo, o juiz atuaria tal qual um legislador intersticial e consciencioso. No entanto, o modelo de regras, próprio da perspectiva positivista, não identifica como válidos esses padrões extrajurídicos. Isso porque tais soluções não podem ser enquadradas como regras. Aproximam-se muito mais do conceito de princípios, uma vez que a solução frequentemente é buscada em critérios como analogia, equidade e standards gerais de justiça. Esse modo de decidir é utilizado especialmente quando se está diante dos chamados casos difíceis, diga-se de passagem, cada vez mais frequentes diante de uma sociedade complexa e especializada.

Assim, Dworkin desenvolve a ideia de que há uma diferença lógica e qualitativa entre regras e princípios, ambos compreendidos como espécies do gênero norma jurídica. Esta compreensão já se difundiu amplamente pela doutrina, de forma que hoje não representa mais uma novidade. Os princípios possuem a dimensão do peso, valor ou importância que as regras não possuem. Em um conflito entre princípios há de prevalecer aquele de maior peso em relação às contingências e especificidades do caso concreto. Por outro lado, um conflito entre regras se resolve no plano da validade. Só uma das regras em conflito poderá ser considerada válida e é o próprio Direito que institui os critérios que podem ser utilizados para resolvê-lo (critério cronológico, critério hierárquico e critério da especialidade). 
Neste sentido, o modelo oferecido pelo positivismo (o Direito como um sistema complexo de regras primárias e secundárias) não consegue explicar a realidade jurídica dos princípios. Nesse sentido, ao não reconhecer a realidade dos princípios como normas, o positivismo jurídico não conseguiria descrever o direito existente de forma adequada. Dworkin propõe, assim, o abandono do modelo positivista. Segundo ROSSI (2011, p. 110),

o abandono do modelo positivista se daria visto que, em primeiro lugar, o positivismo (especialmente o hartiano), ao desconhecer a realidade dos princípios como norma, não descreve o direito existente de maneira adequada. Segundo, pela não valorização do papel dos princípios, o positivismo jurídico entenderia que, quando não há regra jurídica, mediante o caso concreto, que ofereça solução ao problema, o juiz estaria autorizado a buscá-la em um espaço de discricionariedade no qual recorreria a padrões não jurídicos para esta resolução. Terceiro, a regra de reconhecimento não se presta a identificar os princípios, portanto falha como critério de identificação e reconhecimento do próprio direito.

Para Dworkin, o modelo de regras e princípios permite encontrar soluções jurídicas para os casos que as regras, sozinhas, não resolvem - a menos que se recorra a padrões extrajurídicos. Assim, os juízes, perante os casos difíceis, revelariam o direito das partes, e não o criariam efetivamente. Nesse sentido, não há discricionariedade para Dworkin, visto que, nos casos difíceis, quando não encontrada a solução nas regras jurídicas, o juiz se vale dos princípios normativos. Ao fazê-lo, encontra a solução no próprio ordenamento. Não é necessário sair do sistema jurídico, tampouco recorrer a padrões não jurídicos. Não é demasiado lembrar que os princípios são padrões normativos que, ao portarem os valores essenciais de uma determinada comunidade, se estabelecem comumente como direitos fundamentais.

Os princípios constitucionais acolhem, assim, os principais valores e opções políticas da comunidade. Os direitos humanos 
fundamentais muitas vezes são erigidos sob a forma de princípios normativos. A compreensão mais extensa de Dworkin sobre o que é o Direito, em uma perspectiva interpretativa, não se explica e nem se compreende sob a visão do positivismo jurídico. Com efeito, um dos pressupostos metodológicos que acode a toda a doutrina positivista (e são os mais variados tipos de positivismo existente) é a separação entre Direito e Moral. Assim, a compreensão dos princípios normativos, com a sua potencial recorrência a valores e opções políticas fundamentais, quebra esta suposta separação, ainda mais quando se encontram estes princípios em uma Constituição que se estabelece no centro de importância e significado de toda a ordem jurídica, irradiando os seus princípios constitucionais na compreensão e interpretação do sistema jurídico e, consequentemente, rematerializando e ressubstancializando todo o Direito.

\section{Breves considerações sobre as relações necessárias entre direito e moral na perspectiva de Robert Alexy}

É possível afirmar que a perspectiva pós-positivista questiona a tese das fontes sociais do direito, a tese da conexão entre direito e moral (se esta conexão é apenas contingente) e a existência ou não de espaços de discricionariedade na tomada de decisão judicial. Todas essas teses se encontram entrelaçadas, mas, sem dúvida, a mais polêmica e fundamental, no sentido de que se for superada faz com que o positivismo jurídico perca a sua identidade, é exatamente, a tese das relações entre o direito e a moral, que para os positivistas consiste na tese da separação conceitual entre ambos.

Nesta perspectiva se encontra não apenas Alexy, mas todos os autores que defendem a ideia de que a moral desempenha um papel necessário na identificação do próprio direito e, sendo assim, a relação entre ambos é conceitual, no sentido de que não se pode compreender o Direito sem apelo à moral. Este tipo de compreensão estaria na seara do chamado pós positivismo, desenvolvida por autores considerados não positivistas. 
Para Robert Alexy (2009, p.43), todo sistema jurídico carrega em si uma pretensão de correção ou de justiça sem a qual ele não pode ser identificado como jurídico. Este fato é que caracterizará a relação conceitual e necessária entre a moral e o direito. É necessário, no entanto, compreender que, segundo o autor, as teorias não positivistas não excluem do conceito de direito os elementos de legalidade conforme ao ordenamento e a eficácia social. Por outro lado, acrescentam a ele também elementos morais, ou seja, a correção material de seu conteúdo.

Para o autor, o argumento da correção constitui a base do argumento da injustiça e do argumento dos princípios. É, portanto, de fundamental importância. $\mathrm{O}$ argumento positivista contrário à pretensão de correção sustenta que o Direito não se encontraria absolutamente vinculado a esta pretensão. Para Alexy, pelo argumento da correção material, tanto as normas e decisões jurídicas individuais quanto os sistemas jurídicos propriamente ditos formulam necessariamente uma pretensão de correção. Assim, sistemas jurídicos que não formulam uma pretensão de correção não são sistemas jurídicos (conexão classificadora) e os sistemas jurídicos que a formulam, mas não a satisfazem, são defeituosos (conexão qualificadora). Quanto às normas e decisões judiciais individuais, quando não formulam ou não satisfazem uma pretensão de correção, serão juridicamente defeituosas (conexão exclusivamente qualificadora).

Nos processos de criação e aplicação do Direito, os participantes necessariamente têm uma pretensão de correção que é também uma pretensão de correção moral - que quando não é atendida implica uma contradição performativa.

Nesse sentido, para o autor, tanto o direito quanto os participantes do discurso jurídico formulam uma pretensão de correção que possui implicações com a moral e, assim, não se pode deixar de considerar que haveria uma conexão necessária entre a moral e o direito.

Nas suas palavras,

a tese da correção não apresenta dificuldades quando os princípios do direito positivo têm um conteúdo que, moralmente, é exigido 
ou, ao menos admitido. Como exemplos podem servir os seis princípios básicos da Lei Fundamental, ou seja, os princípios da dignidade humana, da liberdade, da igualdade, do Estado de direito, da democracia e do Estado social. Como mandamentos de otimização, esses princípios exigem a sua mais ampla realização possível. Juntos exigem a realização aproximativa de um ideal jurídico, qual seja, o ideal do Estado de Direito Democrático e Social. Sendo esses princípios, ou seus inúmeros subprincípios, pertinentes em um caso duvidoso, o juiz estará juridicamente obrigado a proceder a uma otimização relacionada ao caso concreto. Trata-se, aqui, de dar uma resposta uma questão jurídica, que, por seu conteúdo, também é uma questão de moral política. Ao menos uma parte dos argumentos com os quais o juiz fundamenta a conclusão de sua ponderação tem, quanto ao seu conteúdo, o caráter de argumentos morais. Disso resulta que a pretensão à correção jurídica necessariamente vinculada à decisão inclui uma pretensão à correção moral. Nesse sentido, nos sistemas jurídicos cujos princípios jurídico-positivos possuem um conteúdo moralmente exigido ou ao menos admissível, existe uma conexão necessária entre o direito e a moral correta. (ALEXY, 2009, p. 94)

\section{Direitos humanos fundamentais como horizonte de sentido do próprio direito na perspectiva do neoconstitucionalismo}

Não cabe mais pensar em constitucionalismo, ou no papel desempenhado pelas Constituições contemporâneas, senão no sentido que o Direito se encontra comprometido com valores e opções políticas em um sentido emancipatório de realização das prerrogativas inerentes aos direitos fundamentais e à dignidade humana. Para definir ou conceituar o Direito, hoje, é preciso tomar em conta que este deve estar conceitualmente ligado à realização de determinados valores morais, no cumprimento de determinadas finalidades, que ultrapassam o valor segurança jurídica, sem, no entanto, desconhecê-lo. O Direito deve cumprir uma função emancipatória, estando comprometido com a realidade complexa da qual ele surge e para a qual ele retorna a fim de melhorá-la. 
É verdade que os direitos fundamentais existem desde as declarações de direitos do século XVIII - quando, por razões políticas e sociais múltiplas, pela primeira vez na História reuniram-se simultaneamente os três requisitos necessários para a existência de direitos fundamentais: um Estado que os imponha, um indivíduo (ser moral, independente, autônomo e não essencialmente social) que os titularize e um texto normativo regulando a relação entre Estado e indivíduo (DIMOULIS, 2012, p. 10-11). Foi somente com o neoconstitucionalismo em uma perspectiva pós-positivista, entretanto, que esses direitos tomaram posição central no ordenamento. Formaram, assim, uma ordem objetiva de valores, aberta a princípios e a regras (CAMBI, 2009, p. 87-90).

Apesar do enorme impacto que o neoconstitucionalismo gerou à interpretação e aplicação do direito, a definição de direitos fundamentais - justamente o instituto central do neoconstitucionalismo - ainda é problemática. A vagueza do que se entende por direitos fundamentais prejudica a compreensão e delimitação desses direitos. Principalmente quando se percebe a heterogeneidade dos direitos assegurados no artigo $5^{\circ}$ da Constituição brasileira, que se estende por setenta e três incisos, quatro parágrafos e admite a existência de direitos fundamentais expressos em outros artigos ou implícitos no texto constitucional.

De maneira geral, a doutrina contemporânea busca definir direitos fundamentais a partir de um elemento formal e de um elemento material. Formalmente, para ser considerado fundamental, um direito deve estar previsto na Constituição. Mas isso não basta. Materialmente, seu conteúdo deve remontar, em alguma medida, à dignidade da pessoa humana (HESSE, 1998, p. 254-256; ANDRADE, 1987, p. 85; SARLET, 1998, p. 109; MENDES, 2013, p. 140; PIOVESAN, 2012, p. 84-90; BONAVIDES, 2005, p. 560-562; CUNHA JR., 2010).

A dificuldade surge, exatamente, ao se debruçar sobre o elemento material dessa definição. Por repousar sobre um conceito tão vago como o direito à dignidade, seu conteúdo é indefinível. Canotilho (1998, p. 373), por exemplo, critica a vinculação de direitos fundamentais à noção de dignidade humana. Para ele, a tese 
restringiria as possibilidades de conteúdo dos direitos fundamentais. Seriam fundamentais, de acordo com esse conceito, apenas os direitos com um radical fundado no homem - antropocêntrico, portanto. Já Luís Roberto Barroso (2000, p. 296), em sentido contrário, critica a desmedida amplitude do conceito. $\mathrm{O}$ autor chega a negar qualquer utilidade jurídica ao princípio da dignidade da pessoa humana, visto tratar-se de uma locução de amplitude quase metafísica.

Trata-se aqui do conhecido postulado kantiano segundo o qual todo ser humano é um fim em si mesmo, jamais um meio para atingir finalidade diversa.

Neste ponto, é possível perceber as dificuldades geradas pela vinculação dos direitos fundamentais à dignidade da pessoa humana. Em primeiro lugar, trata-se de conceito muito abstrato, de difícil operacionalização. Em segundo lugar, a reiterada invocação da dignidade da pessoa humana de modo metodologicamente indisciplinado e juridicamente incorreto traz o risco de futilizar um dos valores mais caros ao constituinte (DIMOULIS; MARTINS, 2012, p. 76).

Por esses motivos, parte da doutrina tem adotado um conceito mais aberto de direitos fundamentais, sem atrelá-los à dignidade da pessoa humana. Seriam fundamentais todos os direitos que a Constituição optou por proteger, expressa ou implicitamente. Os direitos fundamentais, assim, poderiam variar de Estado para Estado, consoante os valores que cada ordenamento entende por cultuar. ${ }^{7}$

Essa vertente, todavia, parece se aproximar perigosamente de um conceito meramente formal. Ainda que se faça menção a valores e conteúdos relevantes, a quem competiria definir esses conteúdos? Obviamente, ao constituinte originário - aquele que detém um poder inicial, ilimitado e incondicionado. Ou seja, àquele que, juridicamente, tudo pode.

Os direitos fundamentais ocupam posição central no sistema jurídico, mas precisá-los com exatidão não é tarefa fácil para a

7 Nesse sentido: SCHMITT, Carl. Teoria de la Constitución. Madri: Alianza Universidad Textos, 1996. p. 179-18; SARLET, Ingo Wolfgang. Teoria geral dos direitos fundamentais. In: SARLET, Ingo Wolfgang; MARINONI, Luiz Guilherme; MITIDIERO, Daniel. Curso de direito constitucional. 2. ed. São Paulo: RT, 2013, p. 280-281; ALEXY, Robert. Teoria dos direitos fundamentais. São Paulo: Malheiros, 2008. 
hermenêutica. Ou se adota um conceito atrelado à dignidade da pessoa humana - esse princípio abstrato e misterioso - ou se retorna a um conceito sem conteúdo.

A opção por uma dessas duas vertentes exige que se aprofunde o estudo da dignidade da pessoa humana. A noção de direitos fundamentais atrelada ao conceito de dignidade da pessoa humana é tão difundida quanto inexplorada. Para compreender o conceito, suas restrições e possibilidades, é preciso desvendar o que há por trás dele. Somente então será possível fazer uma escolha racional entre uma ou outra definição.

\section{A título de conclusão: a dignidade da pessoa humana como horizonte de compreensão dos direitos fundamentais e sentido da ordem jurídica}

Para compreender o conceito de dignidade é necessário refazer, ainda que brevemente, o caminho trilhado por Immanuel Kant, que pioneiramente desenvolveu o postulado da dignidade da pessoa humana.

A filosofia moral de Kant visa a estabelecer um conjunto de normas de comportamento universalmente válidas, independentemente das circunstâncias e do direito legislado. Sua preocupação é voltada ao agir racionalmente ético e moral. Não lhe interessa o que um ordenamento determina ou não fazer. A questão que lhe ocupa é: Para o filósofo, uma conduta ética independe das circunstâncias, interesses ou de quaisquer componentes empíricos. Para ele, a construção de um sistema de justiça deve ser absolutamente racional e, portanto, metafísico, ou seja, derivado da razão pura e justificável por si só (BOBBIO, 2000, p. 82-83).

A esses mandamentos objetivamente válidos, cujo cumprimento é um dever em si mesmo, Kant denomina imperativos categóricos.

$\mathrm{O}$ agir moral, assim, tem como condição e fundamento a liberdade individual. Um ato não é moral por seu conteúdo (o que se faz), mas pela sua intenção (por que se faz). Esse princípio, quase evangélico, decorre da ideia de que um imperativo categórico é inegociável. 
Ele deve ser cumprido porque é um fim em si mesmo. E deve ser cumprido livremente (EALE; ANTISERI, 1990, p. 910-914).

Se uma pessoa, por exemplo, diz a verdade para evitar sua prisão por falso testemunho ou para escapar de uma condenação no pós-vida, sua ação não é moral. Nas duas situações, sua ação foi contingencial, direcionada a um obter benefício (ou a evitar um malefício) futuro. Não foi um agir livre, mas um agir condicionado por fatores externos à vontade - no caso, a coerção jurídica ou religiosa. Conduta ética é somente aquela em que o sujeito escolhe livremente não mentir, simplesmente porque não deve mentir. A conduta se justifica em si mesma.

Em outras palavras, o imperativo categórico se impõe à consciência como simples fato da razão. Somente será moral a conduta livremente autodeterminada - ou, mais precisamente, autodeterminada pela razão pura.

Kant (1785, p. 15) chega então ao problema central: para que possam existir imperativos categóricos, é preciso identificar um valor absoluto - algo que valha por si só, em si mesmo, de maneira universal, atemporal e incondicionada. O filósofo, então, propõe:

Pero si suponemos que hay algo cuya existencia en sí misma posee un valor absoluto, algo que, como fin en sí mismo, puede ser fundamento de determinadas leyes, entonces en ello y sólo en ello estaria el fundamento de un posible imperativo categórico, es decir, de una ley práctica.

Ahora yo digo que el hombre, y, en general, todo ser racional, existe como fin en sí mismo y no sólo como medio para cualesquiera usos de esta o aquella voluntad, y debe ser considerado siempre al mismo tiempo como fin en todas sus acciones, no sólo las dirigidas a sí mismo sino las dirigidas también a los demás seres racionales.

(...) los seres racionales se llaman personas porque su naturaleza los distingue como fines en sí mismos, o sea, como algo que no puede ser usado meramente como medio y portanto, limita todo capricho en este sentido (y es, en definitiva, objeto de respeto). No son éstos, pues, fines subjetivos cuya existencia tiene un valor para nosotros como efecto de nuestra acción,sino que son fines objetivos, es decir, seres cuya existencia es un fin en sí misma, y un fin tal que em su lugar no 
puede ponerse ningún otro fin para el cual debiera éste servir de medio, porque sin esto no habría posibilidad de hallar en ninguna parte nada que tuviera valor absoluto, y si todo valor fuera condicionado y, por tanto, contingente, no podría encontrarse ningún principio práctico supremo para la razón.

A partir dessa construção, Kant (1785, p. 15) chega a seu conhecido postulado: age de tal modo que se relacione consigo mesmo e com qualquer outro sempre como um fim, nunca como apenas um meio. ${ }^{8}$

Eis o ponto central da filosofia moral kantiana: a plenitude da condição humana exige que suas ações sejam livres. O homem deve ser governado por normas autoimpostas e obtidas unicamente com o uso da razão. Em outras palavras, autônomo é o homem governado por imperativos categóricos. Daí porque justiça é, em essência, liberdade. O fim último do direito seria assegurar a plena liberdade, de modo que cada homem possa, no exercício de seu livre arbítrio, adotar a conduta (objetivamente) moral (BOBBIO, 2000, p. 113-121).

$\mathrm{O}$ agir moral exige que toda pessoa seja considerada um fim em si mesma. Ninguém pode dispor de si mesmo ou dos demais. Ou seja, autonomia, para Kant, não é liberdade para fazer o que quiser, desde que não prejudique os demais. Autonomia é agir de modo que não nos coloquemos como objeto dos outros. Nem que coloquemos os outros como simples meios para nossos fins (SANDEL, 2012, p. 163).

É exatamente esse o postulado que foi identificado como conteúdo da dignidade da pessoa humana. Dignidade é, em síntese, o princípio segundo o qual toda pessoa é um fim em si mesma. (SILVA, 2005, p. 37; COMPARATO, 2005; CUNHA, 2002; REALE, 1996.)

Não obstante, a dignidade humana é ainda considerada um conceito aberto e em permanente construção. Em todas as previsões normativas, de caráter constitucional ou internacional, a dignidade humana aparece não como um direito, mas como um princípio fundamental que confere caráter de eticidade aos direitos humanos fundamentais, dando unidade axiológica e sentido sistêmico aos

8 Tradução livre. 
ordenamentos. No caso da Constituição brasileira de 1988, o princípio da dignidade humana é fundamento do Estado (República Federativa do Brasil) e horizonte de sentido e compreensão de todos os direitos que se encontram no Texto Constitucional, e também, fora do catálogo Constitucional. Segundo André de Carvalho Ramos (2014, p. 69) existem dois elementos que integram a ideia de dignidade humana na ordem constitucional brasileira,

há dois elementos que caracterizam a dignidade humana: o elemento positivo e o element negativo. O elemento negativo consiste na proibição de se impor tratamento ofensivo, degradante ou ainda discriminação odiosa a um ser humano. Por isso, a própria Constituição dispõe que "ninguém será submetido a tortura nem a tratamento desumano ou degradante" (art. 5, III) e ainda determina que "a lei punirá qualquer discriminação atentatória dos direitos e liberdades fundamentais" (art. 5, XLI). Já o elemento positivo do conceito de dignidade humana consiste na defesa da existência de condições materiais mínimas de sobrevivência a cada ser humano. Nesse sentido, a Constituição estabelece que a nossa ordem econômica tem "por fim assegurar a todos existência digna" (art. 170, caput).

Assim, é possível afirmar-se que a dignidade é um valor intrínseco ao ser humano, que implica a necessidade de toda pessoa ser tratada com igual respeito e consideração e, o quanto possível, todos devem ter condições materiais básicas de vida, o que se convencionou chamar de acesso ao mínimo existencial.

Observe-se, não ser mais possível e nem sequer desejável que o direito possa ser definido e compreendido sem tomar-se em consideração uma finalidade que lhe deve ser intrínseca e constitutiva. Não basta pensar o que é o Direito desvinculado de uma compreensão teleológica. Interessa saber também que o "direito que é" está comprometido com uma determinado objetivo que ultrapassa a ideia de segurança jurídica. A finalidade é um elemento que também identifica o direito hoje, e a finalidade do direito é o compromisso com a concretização dos direitos humanos fundamentais. Os princípios normativos são chaves que abrem para inúmeras possibilidades de reconhecimento e defesa dos direitos. Ao mesmo tempo, são estes 
mesmos princípios que se constituem em ponte de ligação entre o direito e a moral.

Assim, as Constituições contemporâneas consagram o princípio da dignidade da pessoa humana para afirmar que a pessoa é um valor em si mesmo e que se é possível atribui-se uma finalidade à existência da ordem constitucional seria a de servir de ferramenta normativa no sentido de instrumentalizar a emancipação da pessoa.

\section{Referências}

ALEXY, R. Conceito e validade do direito. São Paulo: WMF Martins Fontes, 2009.

BARROSO, L. R. O direito constitucional e a efetividade de suas normas. Rio de Janeiro: Renovar, 2000.

BARROSO, L. R. Neoconstitucionalismo e constitucionalização do Direito: o triunfo tardio do direito constitucional no Brasil. Revista eletrônica sobre a reforma do Estado, Salvador, n. 9, mar.-mai. 2007.

BOBBIO, N. Direito e Estado no pensamento de Emanuel Kant. São Paulo: Mandarim, 2000.

CAMBI, E. Neoconstitucionalismo e neoprocessualismo. São Paulo: RT, 2009.

CANOTILHO, J. J. G. Direito Constitucional e Teoria da Constituição. Coimbra: Almedina, 1998.

CASSIRER, E. A filosofia do iluminismo. 3. ed. Campinas: Editora da Unicamp, 1997.

DIMOULIS, D.; MARTINS, L. Teoria geral dos direitos fundamentais. 4. ed. São Paulo: Atlas, 2012.

DWORKIN, R. Levando os direitos a sério. 2.ed. São Paulo: Martins Fontes, 2007.

GIRARD, R. Coisas ocultas desde a fundação do mundo: a revelação destruidora do mecanismo vitimário. São Paulo: Paz e Terra, 2008. 
HESPANHA, A. M. Cultura jurídica europeia: síntese de um milénio. Florianópolis: Fundação Boiteux, 2005.

KANT, I. Fundamentación de la metafísica de las costumbres. Escuela de Filosofía Universidad ARCIS, 1785.

MENDES, G. F. Direitos fundamentais e controle de constitucionalidade. 3. ed. São Paulo: Saraiva, 2009.

PEREIRA E SILVA, R. Reflexões sobre a pré-compreensão constitucional: a dignidade da pessoa humana como condição de possibilidade de sentido. In: Revista Sequência, n. 50, jul. 2005.

REALE, G.; ANTISERI, D. História da filosofia: do humanismo a Kant. 2. ed. São Paulo: Paulus, 1990. v2.

RAMOS, A. C. Curso de direitos humanos. São Paulo: Saraiva, 2014.

ROSSI, A. C. S. Neoconstitucionalismo: ultrapassagem ou releitura do positivismo jurídico? Curitiba: Juruá, 2011.

SANDEL, M. Justiça. Rio de Janeiro: Civilização Brasileira, 2012.

SILVA, J. A. Comentário contextual à Constituição. São Paulo: Malheiros, 2005.

SILVA, O. B. Processo e ideologia. Rio de Janeiro: Saraiva, 2004.

Recebido: 24/10/2015

Received: $10 / 24 / 2015$

Aprovado: 03/02/2016

Approved: 02/03/2016 
